\title{
Fractures of the acetabulum: from yesterday to tomorrow
}

\author{
Matej Cimerman ${ }^{1}$ (D) $\cdot$ Anže Kristan ${ }^{1} \cdot$ Marko Jug $^{1} \cdot$ Matevž Tomaževič $^{1}$
}

Received: 29 July 2020 / Accepted: 8 September 2020 / Published online: 22 September 2020

(C) The Author(s) 2020

\begin{abstract}
Purpose The aim of this article is to present history, state of the art, and future trends in the treatment of acetabular fractures. Methods Review of recent and historical literature.

Results Acetabular fractures are difficult to treat. The first descriptions of this injury already appeared in ancient Greek history, but intensive development started in the second half of the twentieth century after Judet and Letournel's seminal work. Their classification is still the gold standard today. It is actually a pre-operative planning system and is used to determine the most appropriate surgical approach. The therapy of choice for dislocated fractures is open reduction and internal fixation. Recent modern techniques based on high-tech computerized planning systems and 3D printing have been successfully integrated into orthopaedic trauma practice.

Conclusion There is no ideal surgical approach for acetabulum fracture treatment, so new approaches have been developed in recent decades. The best outcome series have shown good or excellent results, between 70 and $80 \%$.
\end{abstract}

Keywords Acetabulum $\cdot$ Fracture $\cdot$ Planning $\cdot$ Approaches $\cdot$ History

\section{Introduction}

Acetabular fractures are among the most demanding injuries treated by orthopaedic trauma surgeons. The incidence is three patients/100,000/year [1], so even in a busy European trauma centre, the case load is relatively small and it is difficult to gain enough experience. There are a lot of challenges in acetabular fracture surgery. The 3D morphology of the fracture is complex, and the choice of surgical approach is not always straightforward. Surgical approaches are demanding, and anatomical reduction, which is the most decisive factor for good long-term outcome [2], can pose difficulties, even for the most experienced surgeons. In this review article, we summarize the development and state of the art of the surgical treatment of acetabular fractures.

\section{Historical overview}

The first and for a long time the only description of acetabular fracture came from Homer's Iliad, written during the eighth

Matej Cimerman

matej.cimerman@kclj.si

1 Traumatology Department, Division of Surgery, University Medical Centre Ljubljana, Ljubljana, Slovenia century BC. The poetic description of acetabular injury in Iliad is as beautiful as it is accurate and should be read by every acetabular surgeon: "Just as Diomedes hefted a boulder in his hands, a tremendous feat - no two men could hoist it, weak as men are now, but all on his own he raised it high with ease, flung it and struck Aeneas's thigh where the hip bone turns inside the pelvis, the joint they call the cup - it smashed the socket, snapped both tendons too, and the jagged rock tore back the skin in shreds. The great fighter sank to his knees, bracing himself with one strong forearm planted against the earth, and the world went black as night before his eyes" [3].

Besides the poetic beauty, there are some astonishing facts: exactly the same mechanism of injury; i.e. a direct blow to the greater trochanter was described in an experimental study by Pearson 2800 years later [4], and the description of the pain is astonishingly real.

Four centuries after Homer, Hippocrates described injuries around the acetabulum under the common term "hip dislocations" [5] because it was impossible to differentiate between an acetabulum fracture and hip dislocation by clinical examination alone. Acetabular fractures were considered to be hip dislocations until the nineteenth century. The first detailed description of an acetabular fracture before the discovery of X-rays (W. Roentgen 1896) was made by Sir Astley Cooper in 1818. The diagnosis was made on autopsy. Cooper described a fracture of the innominate bone with central 
dislocation [6]. Schroeder, in a systematic article, analyzed 49 cases of fractures with central dislocations [6]. He stated that these are severe injuries caused by high energy, with a mortality rate of around $30 \%$. In the first half of the twentieth century, the treatment of choice was conservative therapy. Urist reported results after treatment of fracture dislocations of the hip in military personnel [7]. He suggested open reduction and internal fixation for dislocated fractures. Eliot and Knight reported on operatively treated central acetabular fractures $[8,9]$. Despite these reports, the majority of patients were treated conservatively. Rowe and Lowell published an end-result study on 99 patients and recommended conservative therapy [10]. In 1964, Eichenholtz described the current situation: "There are wide differences in opinion on the relative merits of the two forms of therapy, and among the advocates of open treatment there is no agreement as to the type of surgical procedure indicated" [11]. In such an atmosphere, Judet and Letournel began their revolutionary work on this topic. The biggest stimulation to their study was their "extreme disappointment" [12] with the results of conservative treatment. In 1963, they published their classical article with the informative title "Fractures of the Acetabulum, Classification and Surgical Approaches for Open Reduction" [13]. They described their classification, which enables understanding of the complex 3D geometry of a fracture, allowing a logical choice of operative approach. They also developed two new surgical approaches. They recommended open reduction and internal fixation for all displaced acetabular fractures [14]. It took several more years for this idea to be widely accepted. There was a lot of scepticism about the operative treatment of acetabular fractures in North America in the 1970 s, and some literature still advocated conservative treatment $[15,16]$. However, Judet and Letournel continued the dissemination of their ideas. They published their textbook in English translation in 1981 and a revised edition in $1993[12,17]$. These textbooks became very popular and are still today considered to be "the bible" of acetabular surgeons. Letournel was active as an educator. $\mathrm{He}$ was a guest of honour at $\mathrm{AO}$ (Arbeitsgemeinschaft für Osteosynthesefragen) courses in Davos in 1982, and started courses of pelvic surgery in Paris and North America. In the 1980s, he trained a group of five North American surgeons, who were later called the acetabular club [12]. They spread Letournel and Judet's teachings in North America and also worldwide. One of them, Joel Matta, later published the largest single surgeon outcome study of operatively treated acetabular fractures [18]. The era of modern acetabular surgery had started. At our institution, we performed the first documented internal fixation of a posterior wall fracture in 1965, followed by systematic development of pelvic and acetabular surgery.
Classification, decision-making, and planning

Judet and Letournel introduced their classification of acetabular fractures in 1964 and made a slight refinement in 1974 $[14,17]$. The classification is the gold standard, has definitely stood the test of time, and is the preferred classification for the majority of orthopaedic trauma surgeons [19]. Before their classification, the morphology of acetabular fractures was poorly understood. Letournel wrote that the choice of operative approach was more or less a "toss-up" [12]. The choice of approach is important, because no single surgical exposure allows convenient access to both columns without consequences. He realized that the problem was not the operative approach per se, but the inability "to grasp the precise outline of the fracture from traditional AP radiographs" [12]. After an intensive study of the anatomy of the innominate bone, they developed the concept of two columns, which is the cornerstone of their classification. The beauty of their classification is that it is in fact a pre-operative planning system and is used to determine the most appropriate treatment, especially the right surgical approach. From three standard X-ray projections (AP, iliac, and obturator) and four lines (iliopectineal, ilioischial, both walls), it is possible to understand the 3D morphology of fractures and classify them into five elementary and five associated types. Elementary fractures are those in which a part or all of one column is detached (posterior column, posterior wall, anterior column, anterior wall, transverse), and associated fractures include at least two of the elementary forms (T-shaped, transverse with posterior wall, posterior column with posterior wall, anterior column with posterior hemitransverse, and both columns) [12].

Intra- and interobserver reliability was high in an expert group but lower with less-trained surgeons [20-22], giving the impression that the classification system is too difficult and complex. The difficulty and complexity probably came from the challenging nature of acetabular fractures, rather than being inherent to the classification system [19]. The learning curve can be long, but it is possible to shorten it using an algorithmic approach [23, 24], 3D CT, and modern 3D modules [25-27].

Accurate classification of acetabular fractures is therefore possible on the basis of conventional X-rays and is the first step in decision-making. The second step is a 2D CT scan, which can detect many important details that are not included in the classification: small intra-articular fragments, impactions, quantifying intra-articular step and gap, discrete fractures of the femoral head, and subluxation $[28,29]$. The whole imaging process is concluded with 3D CT. The 3D is easily correlated with a plain radiograph and provides a unique perspective of the fracture [30]. A decision on treatment is now possible. The indications for operative treatment according to Letournel are straightforward: all dislocated acetabular fractures [12]. Nowadays, we have some evidence for quantifying a dislocation. Jenssen et al. 
demonstrated in a study of 186 hips that conservatively treated acetabular fractures with less than 2-mm displacement had 94\% survival after 10 years [31]. Matta found $91 \%$ good or excellent results in operated patients with less than 3-mm displacement [32]. Other generally accepted indications for operative treatment include as follows: the acetabular articular surface is intact in the superior $10 \mathrm{~mm}$ of the joint on CT evaluation, congruent hip joint [33], intra-articular fragments, and unstable hip. The ideal timing for operation according to Letournel is from two to six days after the injury [12]. Mears confirmed this interval, demonstrating that anatomic reduction is significantly decreased after a delay of more than 11 days [34]. A surgeon therefore has only a short time for pre-operative planning. Jeffrey Mast, a legend of preoperative planning in fracture surgery and the co-author of a best-selling textbook about planning [35] said: "The construction of ships, automobiles... involves sophisticated plans rendered in drawings to the most minute detail. These systems are designed to discover flaws in the project beforehand. A similar system in orthopaedic surgery is also possible" [36]. Judet and Letournel had done exactly the same 20 years earlier and one can admire the precise drawings of complex acetabular fractures in their textbook [12]. Planning enables an understanding of the fracture lines in detail, the choice of the right operative approach, and an outline of surgical tactics. Modern techniques based on high-tech computerized planning systems have been successfully integrated into orthopaedic trauma practice [37-40]. In 2007, we introduced an experimental computer program at our institution, for the virtual operation of acetabular fractures based on real data [37]. The module consists of a $3 \mathrm{D}$ viewing tool and a simulation tool based on DICOM data from 1.5-mm CT slices. Segmentation of each fracture fragment can be performed in a different colour. Manipulation of the fragments in 3D, with virtual reduction and fixation, is possible. The plates are automatically contoured to reduce the acetabulum. The direction and length of the screws can be controlled. Intra-operative fluoroscopy can also be simulated. It is possible at the end to compare the planned and real procedures. Surgeons are generally satisfied with virtual 3D planning [37, 41]. Chen et al. demonstrated a better clinical outcome in patients operated with planning and 3D modelling than in the conventional group [42] and Citak described better reduction on plastic models after $3 \mathrm{D}$ virtual planning [38]. The next logical step is to connect $3 \mathrm{D}$ virtual planning with $3 \mathrm{D}$ printing, which means creating a real 3D model from a digital image [43]. The digital image can be converted to a.stl (StereoLitography) file and sent to a 3D printer. This technology is becoming more and more accessible and affordable and is already a mainstream in many fields of medicine [43]. A 3Dprinted model of a fractured acetabulum allows the surgeon tactile and visual understanding of the specific fracture. Models also allow pre-operative simulations of difficult fracture reduction and fixation and greatly facilitate education [44]. The plates can be shaped according to a bone model pre-operatively, better to match the reduced fracture during the surgery. [45]. In our institution, we plan the fixation on a virtual model and bend the plates according to the reduced acetabulum. We then print models of the plates from plastic and use them as templates for contouring the real plates. We have found this technique to be very useful (Fig. 1). Technically it is now possible to print patient-specific custom-made plates from titanium. We have also demonstrated that different surgeons designed different implants for the same fracture, so these implants were patient and surgeon specific [46]. The next step can therefore be the printing of real implants according to the patient-specific anatomy, surgeon's aspirations, and optimal biomechanical properties.

\section{Surgical approaches}

The functional outcome of operatively treated acetabular fractures depends directly on the accuracy of reduction $[12,18$, 32], and the most decisive factor for performing the best reduction possible is the right choice of surgical approach [47]. The approach in acetabular fracture surgery poses specific problems: first of all, the acetabulum lies deep and is covered by important neurovascular structures, which makes the approach technically demanding and sometimes risky. Secondly, no single approach allows access to the entire acetabulum [48]. Judet and Letournel were aware of this more than half a century ago, when they started to understand the complex geometry of acetabular fractures. For posterior fractures, they used the Kocher-Langenbeck approach and they looked for an approach for the anterior column. After a serious study in an anatomy lab, Letournel introduced the ilioinguinal approach (IL) and started to use it in 1965 [12]. The approach is composed of three windows. The first window provides access to the internal iliac fossa and sacroiliac joint. The second or middle window grants access to the pelvic brim and quadrilateral surface from above, and the third window, medial to the iliac external vessels, gives access to the superior pubic ramus. The approach allows a complete access to the anterior column [12]. IL is extensive and technically demanding and needs a long learning curve. When the authors began also to treat delayed cases, they felt the need for simultaneous exposure of both columns, and ten years later, they introduced the extended iliofemoral approach. This approach enables access to the whole external surface of the iliac bone and is anterior limited by the iliopectineal eminence [12]. The approach is very extensile and demanding. These three approaches became the gold standard for acetabular fracture surgeons and have remained so until today. Despite favourable long-term results for experts using the mentioned approaches $[12,18]$, the development of new approaches and improvement of classic approaches have been obvious in recent decades. First of all, there has been a decline in using extensile 

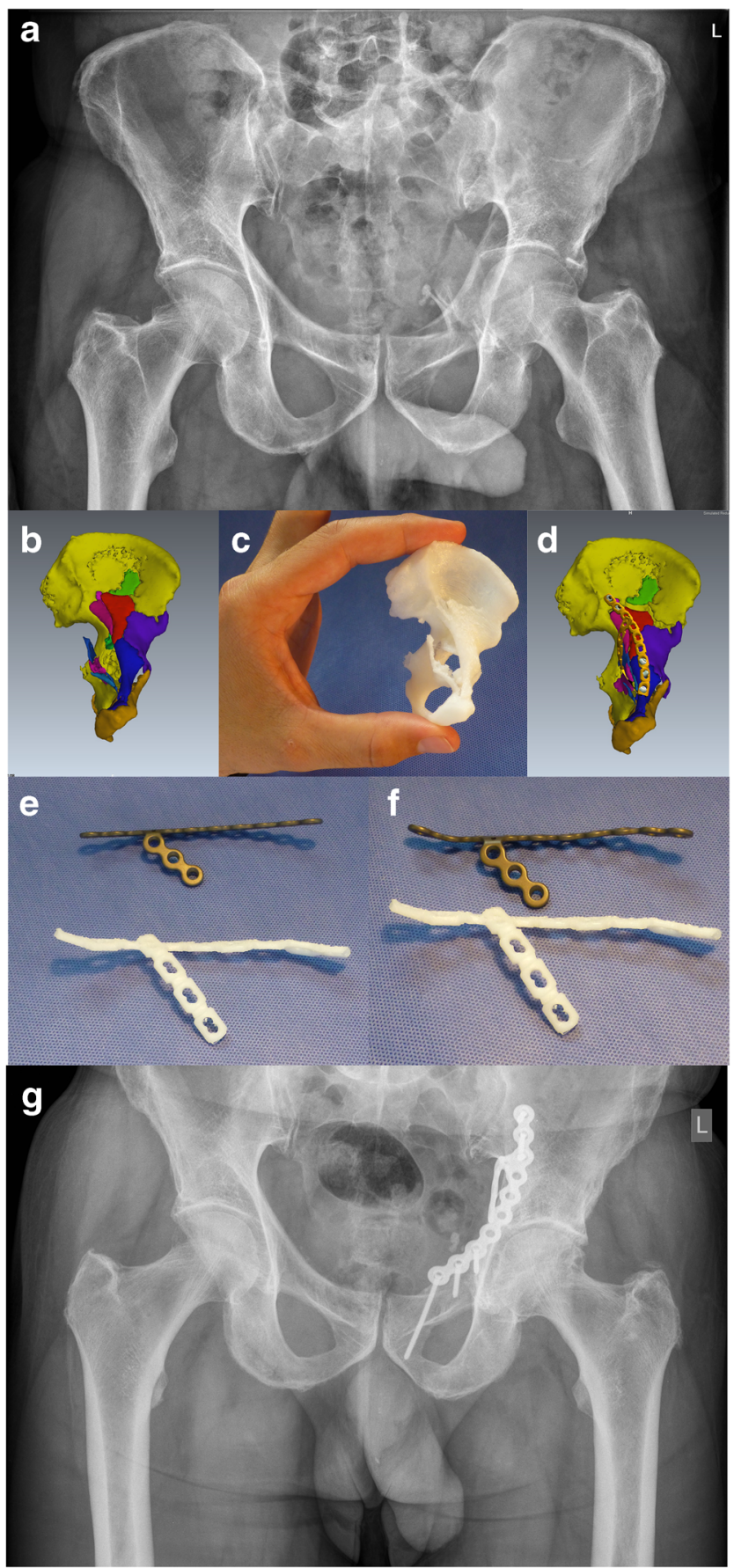

Fig. 1 Process of 3D planning: a comminuted anterior column fracture of the acetabulum in a 65-year-old male, $\mathbf{b}$ fracture segmentation using preoperative planning software, $\mathbf{c}$ a reduced size 3D-printed model enables visual and tactile understanding, $\mathbf{d}$ virtual reduction and individual designed shape of the plate, $\mathbf{e}$, f individual designed 3D-printed plastic plates according to virtually reduced fracture serves as a template to contour reconstruction plates, $\mathbf{g}$ result 3 years after open reduction and internal fixation (the Pararectus surgical approach was used)

approaches. While in his original series, Letournel used an extended iliofemoral approach in $14 \%$ of patients [49] and Matta in 22\% [50], and in a meta-analysis from 1966 until 2004 , extensile approaches were still used in $17 \%$ of cases
[51], more recent studies have shown a marked decline in the use of extensile approaches to $4 \%$ [52] and to $0.4 \%$ in a study from UK [53]. Extensile approaches are associated with a prolonged operative time, blood loss, high percentage of heterotopic ossifications, and wound complications, even in the most expert hands [54-56]. New generations of acetabular surgeons use extensile approaches less and less. If a surgeon is not comfortable with large approaches, he is not likely to use them even in rare cases. This is a self-accelerating phenomenon and it is possible that young acetabular surgeons in future will see extensile approaches only in textbooks and cadaveric labs [47]. It is perhaps easier to be familiar with anterior and posterior approaches and combine them in complex cases. Equally, improvements in the posterior approach, the development of new anterior approaches, and better pre-operative planning have pushed the limits of a single approach forward.

Moed described a modified Gibson approach to the posterior column [57]. The approach is similar to KocherLangenbeck and differs only in its proximal dissection: the interval between the tensor fasciae latae and gluteus maximus is developed and the gluteus maximus is displaced from its anterior border without splitting. This protects the neurovascular supply to the anterior part of the muscle. The approach also enables better visualization of the anterosuperior part of the acetabulum and can be combined with trochanter flip osteotomy. Gautier et al. from the Bernese group studied the anatomy of the medial circumflex artery in detail [58]. They demonstrated a constant course of the deep branch of the medial femoral circumflex artery in the extracapsular segment. This pivotal work enabled a safer approach to the posterior column and also makes possible trochanter flip osteotomy, with or without surgical dislocation of the hip [59]. Ganz published a unique series of 213 surgical dislocations of the hip without a single avascular necrosis of the femoral head [59]. Trochanteric flip osteotomy without surgical dislocation of the hip allows safe exposure of the posterosuperior and superior parts of the posterior column without damage to the abductor muscles [60]. The osteotomy is balanced by the opposite pull of the gluteus medius and vastus lateralis muscle. Surgical dislocation of the hip makes possible direct visual control of the acetabulum during reduction and fixation $[61,62]$ and can be used in the surgical treatment of femoral head fractures [63].

In 1993 and 1994, Hirvensalo et al. [64] and Cole and Bolhofner [65] independently describe a new anterior approach, which is now called the anterior intra-pelvic approach (AIP). In AIP, the recti muscles are split at the midline and further dissection is performed extraperitoneally direct to the posterior aspect of the pubis to the quadrilateral surface. The iliopectineal fascia is released from the pelvic brim, the femoral vessels are moved anterior, and the inner surface of the true pelvis is exposed. The main difference of IL is that in AIP, there is no medial window and the surgeon stands on the opposite 
side of the fracture and "looks in" while in IL, the surgeon remains on the injured side and "looks over" [47]. If the fracture extends to the iliac wing, it is possible with AIP to open the first (iliac) window of the ilioinguinal approach and use it for reduction and fixation of the iliac wing [65]. The new AIP approach has become more and more popular worldwide. There are several reasons for this rising popularity: it is potentially less invasive than IL and enables excellent visualization of the entire pelvic brim from the pubic body to the sacroiliac joint, including direct visualization of the quadrilateral plate [66]. The new approach is therefore very suitable for anterior fractures, including central luxation, which is essentially a typical geriatric fracture pattern. These fracture patterns are more and more frequent because of the rapidly growing elderly population [67], and the treatment strategy should be adapted to this. Dissemination of the AIP approach has also encouraged the development of new instruments and implants [68]. It is difficult to compare surgical approaches, but a study by Rocca et al. and meta-analysis by Meena et al. both favour AIP over IL [69, 70]. The Bernese group recently contributed a new anterior approach called Pararectus [71, 72]. The approach combines the advantages of intra-pelvic and ilioinguinal approaches. It is technically demanding and, although the first results are promising [73], further studies are needed.

It would be ideal for an acetabular surgeon to master all the approaches (classic and novel), because they are complementary not competitive and enable specific details for specific fractures. However, in practice, because of the relatively low case load, the majority of surgeons master a limited number of approaches. The approach should therefore be chosen according to fracture pattern, soft tissue status, and the individual preference and skill of the surgeon. From 2002 to 2020, we operated 361 acetabular fractures; an intra-pelvic approach was used in 142 (39\%), Kl or Gibson with or without trochanteric flip in 184 (51\%), a combination of anterior and posterior in $23(6 \%)$, Pararectus in four $(1 \%)$, and ilioinguinal in three (1\%) (unpublished data).

\section{Outcome}

Numerous outcome studies have shown good or excellent results, between 70 and $80 \%$. The best results and the biggest series were presented by Letournel [12] and Matta [18], 491 and 816 hips, respectively. Matta also analyzed the survival of hips, which was $85 \%$ for ten years and $79 \%$ for 20 years. These long-term results appear largely unchanged and still represent the gold standard. It is a question why the results from Letournel have not really been bettered, despite the intensive development of acetabular surgery. One reason is a significant change in age and fracture pattern. The number of elderly patients and anterior fracture patterns has risen significantly in recent decades [52, 67]. Anterior patterns, especially anterior wall fractures, have the worst long-term results
$[18,51]$ and to fix osteoporotic bone is also harder. It is necessary to wait some more years for long-term results by surgeons from the new generation. However, in the last decade, there has been a significant drop in iatrogenic nerve injuries and surgery is performed earlier [74].

\section{Conclusions}

The modern era of acetabular surgery started in the 1960s after Judet and Letournel's classic work. There has been intensive development in recent decades. New imaging modalities, including 3D CT, have helped in understanding complex fracture patterns. Computer technology has enabled precise pre-operative planning. The most recent technology has made real even a tactile and visual feeling of the fracture via printed models. Surgeon and patient-specific implants will soon be able to be printed. The classic posterior approach has been refined, and new anatomic knowledge allows safe surgical dislocation of the hip. Modern anterior approaches are promising and are very useful, especially in rapidly growing geriatric anterior fractures. Even in the best hands, good results do not exceed $80 \%$, leaving a lot of room for improvement.

Acknowledgements The authors thank to Radoš Vidmar for collecting the data, Martin Cregeen for language editing of the paper, and Darij Kreuh and Uroš Vovk from Ekliptik 1.t.d. for developing the software and $3 \mathrm{D}$ printing. The authors also thank Aleš Fischinger, MD, for help with the photography.

Code availability Not applicable

Authors' contributions Matej Cimerman: Concept of the article, writing, leading author

Anže Kristan: Abstract, data from clinical department, reviewing of the article

Marko Jug: Reviewing of the article, literature search

Matevž Tomaževič: Reviving of the article, editing, artwork

Data availability This is a review paper. Data stated by our hospital is available by the request to the authors.

\section{Compliance with ethical standards}

Conflict of interest The authors declare that there are no conflicts of interest.

Ethics approval Not applicable

Consent to participate Not applicable

Open Access This article is licensed under a Creative Commons Attribution 4.0 International License, which permits use, sharing, adaptation, distribution and reproduction in any medium or format, as long as you give appropriate credit to the original author(s) and the source, 
provide a link to the Creative Commons licence, and indicate if changes were made. The images or other third party material in this article are included in the article's Creative Commons licence, unless indicated otherwise in a credit line to the material. If material is not included in the article's Creative Commons licence and your intended use is not permitted by statutory regulation or exceeds the permitted use, you will need to obtain permission directly from the copyright holder. To view a copy of this licence, visit http://creativecommons.org/licenses/by/4.0/.

\section{References}

1. Laird A, Keating JF (2005) Acetabular fractures: a 16-year prospective epidemiological study. J Bone Joint Surg Br 87:969-973. https://doi.org/10.1302/0301-620X.87B7.16017

2. Ziran N, Soles GLS, Matta JM (2019) Outcomes after surgical treatment of acetabular fractures: a review. Patient Saf Surg 13: 16. https://doi.org/10.1186/s13037-019-0196-2

3. Homer KB (1998) The Iliad, Reissue edition. Penguin Classics, New York

4. Pearson JR, Hargadon EJ (1962) Fractures of the pelvis involving the floor of the acetabulum. J Bone Joint Surg Br 44-B:550-561

5. Prevezas N (2007) Evolution of pelvic and acetabular surgery from ancient to modern times. Injury 38:397-409. https://doi.org/10. 1016/j.injury.2007.01.035

6. Schroeder WE (1909) Fracture of the acetabulum with displacement of the femoral head into the pelvic cavity. Q Bull Northwest Univ Med Sch 11:9-42

7. Urist MR (1948) Fracture-dislocation of the hip joint; the nature of the traumatic lesion, treatment, late complications and end results. J Bone Joint Surg Am 30A:699-727

8. Elliott RB (1956) Central fractures of the acetabulum. Clin Orthop 7:189-202

9. Knight RA, Smith H (1958) Central fractures of the acetabulum. J Bone Joint Surg Am 40-A:1-16 passim

10. White G, Kanakaris NK, Faour O et al (2013) Quadrilateral plate fractures of the acetabulum: an update. Injury 44:159-167. https:// doi.org/10.1016/j.injury.2012.10.010

11. Eichenholtz SN, Stark RM (1964) Central acetabular fractures; a review of thirty-five cases. J Bone Joint Surg Am 46:695-714

12. Letournel E, Judet R (1993) Fractures of the acetabulum, 2nd edn. Springer-Verlag, Berlin Heidelberg

13. Judet R, Judet J, Letournel E (1964) Fractures of the acetabulum: classification and surgical approaches for open reduction. Preliminary report. J Bone Joint Surg Am 46:1615-1646

14. Judet R, Judet J, Letournel E (1964) Fractures of the acetabulum. Acta Orthop Belg 30:285-293

15. Barnes SN, Stewart MJ (1976) Central fractures of the acetabulum: a critical analysis and review of literature. Clin Orthop Relat Res 276-281

16. Carnesale PG, Stewart MJ, Barnes SN (1975) Acetabular disruption and central fracture-dislocation of the hip. A long-term study. J Bone Joint Surg Am 57:1054-1059

17. Letournel E, Judet R (1981) Fractures of the Acetabulum. SpringerVerlag, Berlin Heidelberg

18. Tannast M, Najibi S, Matta JM (2012) Two to twenty-year survivorship of the hip in 810 patients with operatively treated acetabular fractures. J Bone Joint Surg Am 94:1559-1567. https://doi.org/10. 2106/JBJS.K.00444

19. Butler BA, Lawton CD, Hashmi SZ, Stover MD (2019) The relevance of the Judet and Letournel acetabular fracture classification system in the modern era: a review. J Orthop Trauma 33:S3-S7. https://doi.org/10.1097/BOT.0000000000001401
20. Beaulé PE, Dorey FJ, Matta JM (2003) Letournel classification for acetabular fractures. Assessment of interobserver and intraobserver reliability. J Bone Joint Surg Am 85:1704-1709

21. Ohashi K, El-Khoury GY, Abu-Zahra KW, Berbaum KS (2006) Interobserver agreement for Letournel acetabular fracture classification with multidetector CT: are standard Judet radiographs necessary? Radiology 241:386-391. https://doi.org/10.1148/radiol. 2412050960

22. Visutipol B, Chobtangsin P, Ketmalasiri B et al (2000) Evaluation of Letournel and Judet classification of acetabular fracture with plain radiographs and three-dimensional computerized tomographic scan. J Orthop Surg (Hong Kong) 8:33-37. https://doi.org/10. 1177/230949900000800107

23. Patel V, Day A, Dinah F et al (2007) The value of specific radiological features in the classification of acetabular fractures. J Bone Joint Surg Br 89:72-76. https://doi.org/10.1302/0301-620X.89B1. 18069

24. Ly TV, Stover MD, Sims SH, Reilly MC (2011) The use of an algorithm for classifying acetabular fractures: a role for resident education? Clin Orthop Relat Res 469:2371-2376. https://doi.org/ 10.1007/s11999-011-1925-8

25. Kanthawang T, Vaseenon T, Sripan P, Pattamapaspong N (2020) Comparison of three-dimensional and two-dimensional computed tomographies in the classification of acetabular fractures. Emerg Radiol 27:157-164. https://doi.org/10.1007/s10140-019-01744-6

26. Boudissa M, Orfeuvre B, Chabanas M, Tonetti J (2017) Does semiautomatic bone-fragment segmentation improve the reproducibility of the Letournel acetabular fracture classification? Orthop Traumatol Surg Res 103:633-638. https://doi.org/10.1016/j.otsr. 2017.03.018

27. Hansen E, Marmor M, Matityahu A (2012) Impact of a threedimensional "hands-on" anatomic teaching module on acetabular fracture pattern recognition by orthopaedic residents. J Bone Joint Surg Am 94:e1771-e1777. https://doi.org/10.2106/JBJS.K.00840

28. Alton TB, Gee AO (2014) Classifications in brief: Letournel classification for acetabular fractures. Clin Orthop Relat Res 472:3538. https://doi.org/10.1007/s11999-013-3375-y

29. Mauffrey C, Stacey S, York PJ et al (2018) Radiographic evaluation of acetabular fractures: review and update on methodology. J Am Acad Orthop Surg 26:83-93. https://doi.org/10.5435/JAAOS-D15-00666

30. Burk DL, Mears DC, Kennedy WH et al (1985) Three-dimensional computed tomography of acetabular fractures. Radiology 155:183186. https://doi.org/10.1148/radiology.155.1.3975401

31. Clarke-Jenssen J, Wikerøy AKB, Røise O et al (2016) Long-term survival of the native hip after a minimally displaced, nonoperatively treated acetabular fracture. J Bone Joint Surg Am 98:1392-1399. https://doi.org/10.2106/JBJS.15.01154

32. Matta JM, Anderson LM, Epstein HC, Hendricks P (1986) Fractures of the acetabulum. A retrospective analysis. Clin Orthop Relat Res 230-240

33. Olson SA, Matta JM (1993) The computerized tomography subchondral arc: a new method of assessing acetabular articular continuity after fracture (a preliminary report). J Orthop Trauma 7:402-413. https://doi.org/10.1097/00005131-199310000-00002

34. Mears DC, Velyvis JH, Chang C-P (2003) Displaced acetabular fractures managed operatively: indicators of outcome. Clin Orthop Relat Res 173-186. https://doi.org/10.1097/00003086200302000-00026

35. Mast J, Jakob R, Ganz R (1989) Planning and reduction technique in fracture surgery. Springer-Verlag, Berlin

36. Mast JW (1983) Preoperative planning in the surgical correction of tibial nonunions and malunions. Clin Orthop Relat Res 26-30

37. Cimerman M, Kristan A (2007) Preoperative planning in pelvic and acetabular surgery: the value of advanced computerised planning 
modules. Injury 38:442-449. https://doi.org/10.1016/j.injury.2007. 01.033

38. Citak M, Gardner MJ, Kendoff D et al (2008) Virtual 3D planning of acetabular fracture reduction. J Orthop Res 26:547-552. https:// doi.org/10.1002/jor.20517

39. Hu Y, Li H, Qiao G et al (2011) Computer-assisted virtual surgical procedure for acetabular fractures based on real CT data. Injury 42: 1121-1124. https://doi.org/10.1016/j.injury.2011.01.014

40. Kovler I, Joskowicz L, Weil YA et al (2015) Haptic computerassisted patient-specific preoperative planning for orthopedic fractures surgery. Int J Comput Assist Radiol Surg 10:1535-1546. https://doi.org/10.1007/s11548-015-1162-9

41. Wang H, Wang F, Newman S et al (2016) Application of an innovative computerized virtual planning system in acetabular fracture surgery: a feasibility study. Injury 47:1698-1701. https://doi.org/ 10.1016/j.injury.2016.05.006

42. Chana-Rodríguez F, Mañanes RP, Rojo-Manaute J et al (2016) 3D surgical printing and pre contoured plates for acetabular fractures. Injury. https://doi.org/10.1016/j.injury.2016.08.027

43. Tetsworth K, Block S, Glatt V (2017) Putting 3D modelling and 3D printing into practice: virtual surgery and preoperative planning to reconstruct complex post-traumatic skeletal deformities and defects. SICOT J 3:16. https://doi.org/10.1051/sicotj/2016043

44. Hurson C, Tansey A, O'Donnchadha B et al (2007) Rapid prototyping in the assessment, classification and preoperative planning of acetabular fractures. Injury 38:1158-1162. https://doi.org/ 10.1016/j.injury.2007.05.020

45. Upex P, Jouffroy P, Riouallon G (2017) Application of 3D printing for treating fractures of both columns of the acetabulum: benefit of pre-contouring plates on the mirrored healthy pelvis. Orthop Traumatol Surg Res 103:331-334. https://doi.org/10.1016/j.otsr. 2016.11.021

46. Tomaževič M, Kristan A, Kamath AF, Cimerman M (2019) 3D printing of implants for patient-specific acetabular fracture fixation: an experimental study. Eur J Trauma Emerg Surg. https://doi.org/ 10.1007/s00068-019-01241-y

47. Rickman M, Varghese VD (2017) Contemporary acetabular fracture surgery: treading water or swimming upstream? Bone Joint $\mathrm{J}$ 99-B:1125-1131. https://doi.org/10.1302/0301-620X.99B9.BJJ2017-0185.R1

48. Cutrera NJ, Pinkas D, Toro JB (2015) Surgical approaches to the acetabulum and modifications in technique. J Am Acad Orthop Surg 23:592-603. https://doi.org/10.5435/JAAOS-D-14-00307

49. Letournel E (1980) Acetabulum fractures: classification and management. Clin Orthop Relat Res 81-106

50. Matta JM (1996) Fractures of the acetabulum: accuracy of reduction and clinical results in patients managed operatively within three weeks after the injury. J Bone Joint Surg Am 78:1632-1645

51. Giannoudis PV, Grotz MRW, Papakostidis C, Dinopoulos H (2005) Operative treatment of displaced fractures of the acetabulum. A meta-analysis. J Bone Joint Surg Br 87:2-9

52. Ochs BG, Marintschev I, Hoyer H et al (2010) Changes in the treatment of acetabular fractures over 15 years: analysis of 1266 cases treated by the German Pelvic Multicentre Study Group (DAO/DGU). Injury 41:839-851. https://doi.org/10.1016/j.injury. 2010.04.010

53. Briffa N, Pearce R, Hill AM, Bircher M (2011) Outcomes of acetabular fracture fixation with ten years' follow-up. J Bone Joint Surg Br 93:229-236. https://doi.org/10.1302/0301-620X.93B2. 24056

54. Harris AM, Althausen P, Kellam JF, Bosse MJ (2008) Simultaneous anterior and posterior approaches for complex acetabular fractures. J Orthop Trauma 22:494-497. https://doi.org/10. 1097/BOT.0b013e3181830d2a

55. Stöckle U, Hoffmann R, Südkamp NP et al (2002) Treatment of complex acetabular fractures through a modified extended iliofemoral approach. J Orthop Trauma 16:220-230. https://doi. org/10.1097/00005131-200204000-00002

56. Griffin DB, Beaulé PE, Matta JM (2005) Safety and efficacy of the extended iliofemoral approach in the treatment of complex fractures of the acetabulum. J Bone Joint Surg Br 87:1391-1396. https://doi. org/10.1302/0301-620X.87B10.16538

57. Moed BR (2010) The modified Gibson posterior surgical approach to the acetabulum. J Orthop Trauma 24:315-322. https://doi.org/10. 1097/BOT.0b013e3181c4aef8

58. Gautier E, Ganz K, Krügel N et al (2000) Anatomy of the medial femoral circumflex artery and its surgical implications. J Bone Joint Surg Br 82:679-683. https://doi.org/10.1302/0301-620x.82b5. 10426

59. Ganz R, Gill TJ, Gautier E et al (2001) Surgical dislocation of the adult hip: a technique with full access to the femoral head and acetabulum without the risk of avascular necrosis. J Bone Joint Surg Br 83-B:1119-1124. https://doi.org/10.1302/0301-620X. 83B8.11964

60. Siebenrock KA, Gautier E, Ziran BH, Ganz R (1998) Trochanteric flip osteotomy for cranial extension and muscle protection in acetabular fracture fixation using a Kocher-Langenbeck approach. J Orthop Trauma 12:387-391. https://doi.org/10.1097/00005131199808000-00004

61. Masse A, Aprato A, Rollero L et al (2013) Surgical dislocation technique for the treatment of acetabular fractures. Clin Orthop Relat Res 471:4056-4064. https://doi.org/10.1007/s11999-0133228-8

62. Tannast M, Krüger A, Mack PW et al (2010) Surgical dislocation of the hip for the fixation of acetabular fractures. J Bone Joint Surg Br 92-B:842-852. https://doi.org/10.1302/0301-620X.92B6.22994

63. Massè A, Aprato A, Alluto $\mathrm{C}$ et al (2015) Surgical hip dislocation is a reliable approach for treatment of femoral head fractures. Clin Orthop Relat Res 473:3744-3751. https://doi.org/10.1007/ s11999-015-4352-4

64. Hirvensalo E, Lindahl J, Böstman O (1993) A new approach to the internal fixation of unstable pelvic fractures. Clin Orthop Relat Res 28-32

65. Cole JD, Bolhofner BR (1994) Acetabular fracture fixation via a modified Stoppa limited intrapelvic approach. Description of operative technique and preliminary treatment results. Clin Orthop Relat Res 112-123

66. Sagi HC, Afsari A, Dziadosz D (2010) The anterior intra-pelvic (modified Rives-Stoppa) approach for fixation of acetabular fractures. J Orthop Trauma 24:263-270. https://doi.org/10.1097/BOT. 0b013e3181dd0b84

67. Ferguson TA, Patel R, Bhandari M, Matta JM (2010) Fractures of the acetabulum in patients aged 60 years and older: an epidemiological and radiological study. J Bone Joint Surg Br 92:250-257. https://doi.org/10.1302/0301-620X.92B2.22488

68. Gras F, Marintschev I, Grossterlinden L et al (2017) The anterior intrapelvic approach for acetabular fractures using approachspecific instruments and an anatomical-preshaped 3-dimensional suprapectineal plate. J Orthop Trauma 31:e210-e216. https://doi. org/10.1097/BOT.0000000000000829

69. Rocca G, Spina M, Mazzi M (2014) Anterior combined endopelvic (ACE) approach for the treatment of acetabular and pelvic ring fractures: a new proposal. Injury 45(Suppl 6):S9-S15. https://doi. org/10.1016/j.injury.2014.10.016

70. Meena S, Sharma PK, Mittal S et al (2017) Modified Stoppa approach versus ilioinguinal approach for anterior acetabular fractures; a systematic review and meta-analysis. Bull Emerg Trauma $5: 6-12$

71. Keel MJB, Ecker TM, Cullmann JL et al (2012) The Pararectus approach for anterior intrapelvic management of acetabular fractures an anatomical study and clinical evaluation. J Bone Joint 
Surg Br 94-B:405-411. https://doi.org/10.1302/0301-620X.94B3. 27801

72. Keel MJB, Siebenrock K-A, Tannast M, Bastian JD (2018) The Pararectus approach: a new concept. JBJS Essent Surg Tech 8

73. Keel MJB, Tomagra S, Bonel HM et al (2014) Clinical results of acetabular fracture management with the Pararectus approach. Injury 45:1900-1907. https://doi.org/10.1016/j.injury.2014.10.040
74. Kelly J, Ladurner A, Rickman M (2020) Surgical management of acetabular fractures - a contemporary literature review. Injury. https://doi.org/10.1016/j.injury.2020.06.016

Publisher's note Springer Nature remains neutral with regard to jurisdictional claims in published maps and institutional affiliations. 